\title{
The great slippery-slope argument
}

\author{
J A Burgess University of Wollongong, New South Wales, Australia
}

\section{Author's abstract}

Whenever some form of beneficent killing - for example, voluntary euthanasia - is advocated, the proposal is greeted with a flood of slippery-slope arguments warning of the dangers of a Nazi-style slide into genocide. This paper is an attempt systematically to evaluate arguments of this kind. Although there are slippery-slope arguments that are sound and convincing, typical formulations of the Nazi-invoking argument are found to be seriously deficient both in logical rigour and in the social history and psychology required as a scholarly underpinning. As an antidote, an attempt is made both to identify some of the likely causes of genocide and to isolate some of the more modest but legitimate fears that lie behind slippery-slope arguments of this kind.

Whenever the question of the legalisation of voluntary euthanasia is raised, the proposal is greeted with a flood of slippery-slope arguments. Here is a recent example from William Reichel and Arthur J Dyck:

'If euthanasia were legalised, might we not then regard certain individuals as unworthy of life? Such a concept laid the foundation of the euthanasia movement that began in Germany before the National Socialist movement and before Hitler's rise to power. This single idea of life devoid of value was influential in the German medical profession's snowballing involvement with euthanasia. Before the Holocaust, physicians were the ones who selected patients and carried out this practice. To those who say "it cannot happen here", we reply: imagine the easy marriage between respect for autonomy - for example, assisting the AIDS patient who requests euthanasia - and the need for greater cost-containment - ie, the patient's care is disproportionately expensive. What begins for the patient's own wishes, may later be endorsed for economic reasons. If euthanasia were legalised, individuals themselves might believe that society does not want them to live' (1).

\section{Key words}

Slippery slopes; euthanasia; genocide; cost-benefit analysis.
If this example is atypical, it is so only because it is more detailed than is usual for arguments of this kind (2). And one finds the argument, in some form or other, almost everywhere in applied ethics: indeed, a book has recently appeared by David Lamb (3) which is structured entirely around the argument which appears there literally dozens of times.

Many slippery-slope arguments in applied ethics are simple in structure, highly specific in scope and modest in the practical counsel they offer us. A good example involves the question whether to prescribe drug $\mathbf{A}$ or drug $\mathbf{B}$ to a patient. For the condition concerned, A might score best on almost all relevant criteria whilst $B$ does adequately on all, if less well on some. Suppose, further, that there is no realistic? possibility of switching drugs in mid-treatment. Now, if A leads to tolerance, eventually needing to be administered in a lethal dose, a simple and sound slippery-slope argument leads to the conclusion that drug B is to be preferred. But, Reichel, Dyck and Lamb (4) - with many others - are not much interested in such modest and intuitively compelling arguments. They prefer to go for broke, offering the 'One Great Slippery-slope Argument' (hereafter, the Great Argument) as the only example of the genre worth writing about. The argument is simple in form: if we adopt such-and-such a particular change in our practices it just might start a slide into a moral deterioration that ends with our committing Nazistyle atrocities. Clearly if such a charge were just and we have already seen that some slippery-slope arguments are good arguments - then this would be a very good reason not to adopt the change, at least if the threat of deterioration were at all serious. Further, we know that such moral degeneration does occur - in Germany under the Nazis, as so often elsewhere, it did occur - so it is always a serious question of great practical importance how such degeneration is caused.

Unfortunately, purveyors of the Great Argument rarely if ever work it into a detailed slippery-slope argument. They rest content with the sketchiest of formulations, leaving the detailed work to their opponents: we've shown you (sketchily) that it might happen; now show us (in detail) that it couldn't. But 
this is a fraud. The mere presentation of a slope does nothing to show that the onus of proof is on the reformer to demonstrate that a proposed change will not lead to disaster. This mistake, although of no great intellectual importance, sophistication or profundity in itself, is nonetheless encountered often enough to deserve analysis and diagnosis and it is clearly of great practical importance, for many have been persuaded of its soundness. At the other extreme we have those who regard any slippery-slope argument as nothing more than a hollow rhetorical flourish. No doubt, the prevalence of sketchy and implausible examples - usually versions of the Great Argument - has led many to this attitude, but we have already seen that some modest slope arguments are good arguments so the attitude must be abandoned. Nevertheless, what we need is what nonextremists have wanted all along: some sound and (preferably) non-technical practical advice in sorting the good slippery-slope arguments from the bad. Here I shall concentrate only on the 'Great Argument' and I shall attempt to show why it is a bad argument.

As a first step towards our objective, we should note two reasons why the slippery-slope argument presented earlier as an example of a good argument was indeed good. First, it was modest: it showed how some particular good could be obtained or some bad avoided. Second, it was detailed. We did not merely gesture obscurely towards the possible existence of a force propelling us down a dangerous slope; we provided enough details for the reader to see that there would indeed be a force operating sufficient eventually to produce disaster if a certain course of action were taken. The two virtues I have isolated are not unconnected: unsurprisingly, slope arguments with modest conclusions are easier to provide with the detail needed for adequate appraisal.

We are now in a position to see why the 'Great Argument' is not a good argument. Its conclusion is highly immodest and it is typically undetailed. Lamb used one or another version of the argument literally dozens of times in his book but nowhere gives a description of the forces purportedly propelling us down the slope sufficiently detailed for us to appraise them for efficacy. Yet the conclusion - that we, as a community, are in danger of complete moral collapse - is one that would appear to require detailed and subtle substantiation.

Was Lamb unaware, then, of the need to provide evidence that the threat of a moral collapse is a serious possibility? He was not entirely unaware of the need to provide evidence - he realised that parallels between social conditions in pluralistic, democratic societies of the present and those prevailing in Nazi Germany are the stuff of which the relevant evidence is made. But the evidence he cites is scattered and fragmentary; a collection of parallels drawn from different places and times: the existence of 'unmeltable ethnics' (ie, potential scapegoats) in contemporary America and the British Commonwealth (5), the Milgram experiments in the USA in the '70s in which some experimental subjects inflicted what they believed to be great pain on others when instructed by scientists to do so (6), jingoism in British newspapers during the Falklands war (7). To invite us to contemplate a slide into Nazi-style atrocities on the basis of evidence presented in this way is like warning us of the danger of a bomb exploding whose explosives are in Sweden, whose casing is in the USA and whose detonator is in Rio.

What, then, is required of a successful slipperyslope argument of the ambitious kind? To be successful, it would simply need the backing of good psychology, political sociology and social history. To achieve this would be no mean feat, of course, and would be of immense value. It would provide us with a genuine insight into the preconditions and causes of communal moral deterioration. This is a phenomenon that is not rare but commonplace - there have been numerous examples since the Nazis - and it would be good to understand how and why it occurs. But the sloppy presentation of slope arguments obscures rather than illuminates these important processes.

I have suggested that ambitious slope arguments are unlikely to be good arguments - their very ambition leads to a fatal lack of detail in formulation. To eliminate the suspicion that this is no more than? a minor defect, let us examine the detailed considerations Lamb does supply.

Lamb has a general consideration which he takes to support his position - a worry about the framing of (laws enshrining) moral positions in vague language. Vague criteria can be stretched - presumably without anyone noticing - until they can be made to apply to cases never intended by the original legislators. There seem to be two kinds of mechanism by which this happens. First, the stretching of a boundary can be on the (hidden) agenda of parties not actively involved in the original proposed reform. So, without needing to attribute sinister motives to someone who advocates, say, euthanasia, on compassionate grounds, such a proposal would be dangerous because of the capacity of those who would take life for less defensible reasons to exploit the lack of a total prohibition against killing. This is an implausible suggestion unless further supported. If legislators are aware of the kinds of active taking of life they do not want to encourage, then they will take care that safeguards are in place clear enough to ensure that opportunistic boundary stretching will be seen for what it is. Since almost all law is couched in part in vague terms, this is a general problem that the legal system has to deal with, but I know of no evidence that the legal system has been rendered impotent by it. In general, even the untrained jury member is able to tell when a vague term has been opportunistically stretched beyond the limits of 
tolerance in force at the time. On reflection, this should be unsurprising. Vagueness pervades the law because it pervades ordinary language and the juror has learnt, as we all have, to look out for opportunistic boundary stretching.

This brings me to the second mechanism. I think that the real worry behind the example we are currently considering must be the fear of a slide through habituation into wholesale killing of a kind the reformers never contemplated legalising. The idea seems to be that medical professionals who engage in euthanasia - and the general public - will come to regard (beneficent) killing as routine. When this occurs, there will be pressure for further liberalisation until we reach a stage where courses of action now regarded as atrocious will then be regarded as permissible. (We will then be, in effect, at the bottom of the slope.)

How likely is a process of this kind to occur? Note first that we must suppose that the original rationale has somehow been lost. If those who practise euthanasia do so for the very reasons that prompted legislative reform, and for no other reason, then we have no reason to fear a slide. Behind the suggestion, however, there seems to be another worry: people who take life for whatever reason will eventually become brutalised. Perhaps they will come to enjoy killing as such; at least they will lose the will to be careful about establishing that a proposed killing is really beneficent. (Perhaps they become addicted to killing.) Now this is a hypothesis in empirical psychology but one which, from the vantage point of this armchair, seems extremely implausible. We know that combat soldiers are trained killers and that part of the training consists in deliberate and systematic dehumanisation. We also know that although some ex-soldiers actually do degenerate in just the way imagined - they become psychopathic killers - this is a relatively unusual outcome. (I am not of course denying that retired combat soldiers do suffer from psychological problems directly attributable to the training and practice of their earlier career.) Even those who are trained to kill are usually fairly discriminating about whom they kill and why: if this were not the case, soldiers would be just as likely to kill their colleagues as the enemy. Actually, it is remarkable just how well most military personnel are able to keep their killing activities quarantined from the rest of their lives. But if trained killers can, to a remarkable extent, be highly selective about suitable targets, why should medical practitioners slide down a slope that soldiers can (usually) resist. The training of the medical practitioners requires no similar dehumanisation - except the minimal training required to overcome squeamishness - and no change in training would be required if we were to legalise euthanasia. Further, one would expect institutionalised medicine to weed out those who would kill for non-beneficient reasons through a system of checks and safeguards and one would expect the required precautions to be enforced by law.

I conclude, then, that those who regard voluntary euthanasia as a step onto a slippery slope that will (probably) lead to disaster have so far failed to make out a case that is at all convincing. Detailed empirical evidence is required and detailed empirical evidence is conspicuously lacking. And the considerations just advanced suggest that the required evidence will not be forthcoming. Further, the ancient Greeks and Romans went in for infanticide, the Eskimos practised patricide, matricide and gendercide without undergoing a gradual slide into wholesale disrespect for human life. (I am not, of course, applauding or advocating these practices. I note only that societies have been able to contain systematic killing even when it is at best only dubiously beneficent.) Of course, these considerations only shift the onus of proof back onto the slope-argument theorist. But that has been precisely my purpose.

All of this leads to the question of what does cause widespread moral deterioration of the kind experienced in Nazi Germany. Several factors seem to me to be present in known cases of this kind. I shall first consider factors that might loosely be described as suitable background conditions. Second, I shall attempt to identify some of the mechanisms by which those conditions can be exploited to implicateo the decent and less gullible members of the society in: the slide towards genocide.

First, the presence of a ruthless totalitarian regime with a self-serving, often religious or pseudoscientific, ideology seems to be one of the frequently encountered features, even if it is not an essential prerequisite. Clearly, total power together with a murderous hidden (or not so hidden) agenda makes the systematic committing of atrocities possible, whether or not the general population approve of what is going on. But here, whatever moral deterioration that has taken place has taken place before the murdering begins; the leaders of the regime have nowhere further to slide.

Second, it is important that the ideology of the ruling regime incorporate an organic theory of the (dominant) social group. The social group might simply be identified with the state or it might be a quasi-mystical racial entity like the Volk, as in Nazi Germany. To treat a social group as an organism leads those who do so to ask after the 'health' of that organism. This encourages the treatment of the individual human beings who make up the group as though they were merely functional - or (crucially) dysfunctional - parts of that organism. Thus reduced, disruptive or unproductive elements will come to seem no more suitable as objects of moral concern than would a diseased appendix or a tumour.

Third, a general and widespread feeling of anxiety about the 'health' of the social organism is clearly 
conducive to moral deterioration of the kind we are considering. There are numerous possible (realistic) causes of anxiety of this kind; post-war demoralisation in '20s Germany, fear of an alien majority in contemporary South Africa and fear of counterrevolution in numerous post-revolutionary societies are just some of the possibilities.

Fourth, it is extremely useful (for the regime) to have a group within the society, clearly identifiable through its 'otherness', to identify as the source of the 'disease'. The group might be a minority - Jews, Gypsies, homosexuals et al in Nazi Germany - or it might be a disenfranchised majority, as in contemporary South Africa or Cambodia under the Khmer Rouge. Only when the target group is a minority does this process appear to be correctly described as scapegoating.

This completes my list of suitable background conditions. Note, however, how intimately connected they are: for genocide to be at all probable a combination of several conditions would seem to be required, for there have been numerous societies that have exhibited one or more of these features without degenerating to anything like the point that made the systematic, medically supervised, atrocities of Auschwitz possible. Clearly, if all of the preceding conditions are satisfied, it would be unsurprising if a hard-core group of supporters of the regime were prepared to accept - even welcome - genocide as a 'cure'. But how might this attitude spread to the broader community? In particular, how might a group of medical professionals be recruited to carry out the regime's genocidal programme?

First, it ought not to be underestimated just how efficacious the skilful and ruthless deployment of threats and terrorist tactics can be in implicating unwilling members of the social group in the programme and in eliminating those courageous enough to resist even these tactics. The successful strategies of the Nazis and of Stalin are well documented.

Second, the development of a bureaucratic structure and (preferably) a technology that facilitates a distancing of the individual from feelings of responsibility for the proposed killings seems to enable otherwise decent people caught up in the programme to perform their functions with less guilt than might be expected.

Finally, the ordinary mechanisms by which corrupt groups perpetuate themselves can lead (sometimes gradually) to a broadening of the group who have morally deteriorated: in brief, a share of power depends on membership in the group but membership in the group requires that the newcomer first engage openly in the corrupt behaviour. Once in, the new member gets locked in, for all the previous members now have on him dirt of precisely the same kind that he has (or will come to have) on them.

It is worth noting that moral deterioration need not be, and probably seldom is, gradual. Initiation into the rigours of army life is sudden, traumatic and brutal and not something that creeps up on the recruit gradually and unnoticed. Contrary to the fears of proponents of the Great Argument, gradual change is much easier to resist - for individuals, if not for groups - than sudden change. Further, when crowds turn nasty and violent there is sometimes a gradual build-up of tension but just as often an eruption can be extremely sudden. It is therefore something of a mystery why purveyors of the Great Argument seem to be more worried about gradual change for the worse than about sudden change for the worse.

Of course, the remarks I have just made do not constitute even a crude analysis of the causes of moral deterioration (8). They are intended only as fairly rough observations about the known aetiology of that phenomenon, but they do indicate the kind of empirical evidence which proponents of the Great Argument might attempt to furnish, were they to make a serious attempt to convince the sceptical. My claim is that until they address these issues with detailed, subtle and scholarly work that would be seen as plausible even by the sceptical, we should not be impressed by the Great Argument and should resist the conclusions about public policy the argument would appear to support.

In reaching this conclusion however, it is impor tant to stress two points. First, I am not claiming that a combination of just some of the factors presented ought not to be cause for concern. There are many destinations short of genocide which we should seek to avoid and if a convincing slope argument can be produced that there is a significant danger of our sliding to such a place, then we should be wary of taking a step in the dangerous direction. Second, I have been concerned here only with slides by large groups into systematic mass killing. Considerably less seems required for small groups and individuals to lapse in this way and less still if the killing is a 'one off' occurrence: it is hard to see how anyone but the most blinkered euphemist could avoid describing the bombing of Dresden or of Hiroshima as mass killing and it seems unnecessary to invoke a slippery slope to explain how these events came about.

One curiosity in the presentation of slope arguments is especially worthy of note. Although Lamb, for example, presents dozens of examples in which a small initial change in our practices purportedly might lead gradually to disaster, no examples are presented in which a small initial change in our practices might lead gradually to a moral utopia, or at least to a vastly morally superior world. Yet any possible moral state of the world can be reached from any other such state through a long enough series of gradual steps, just as any musical pitch can be reached from any other through a sufficiently long glissando. The moral trombone on which Lamb and his ilk play their tunes is apparently capable only of descending glissandi. I have never seen a proponent 
of the Great Argument provide an adequate explanation for favouring this curiously limited instrument. If pressed for an explanation I would proffer the following conjecture: those who offer the Great Argument seem to be entirely ignorant of the vast technical literature on slippery slopes and related phenomena now available. In the ordinary practitioner of applied ethics this is hardly a fault; in a proponent of the Great Argument it is unforgivable.

What, then, is really behind the worries articulated by Lamb and others? One is tempted to say that the Great Argument is the last resort of the irrational conservative - and the more fanciful and paranoid the presentation, the more tempted one is to say this. But I think that there is a deeper fear lurking in the background, that does have a rational basis. One of the major advantages of the use of vague language in the framing of laws and less formal principles is that the application of those laws and principles will change automatically as community attitudes change so there will be no need to change the law to bring it into line with those changed attitudes. This has evident advantages - it is largely this flexibility that makes vague language so useful to us. In a pluralistic society, however, the law rarely if ever reflects wholly the moral position of one group in society rather than another. More likely, it will embody a compromise between the competing positions which reflects the relative political strength of the competing groups. Compromises achieved in this way are rarely if ever syntheses. And a compromise between two coherent moral positions need not itself be a coherent moral position: witness King Solomon's (disingenuous) proposal to resolve the dispute between the women over motherhood of the child. But if a law reflects a compromise that is incoherent in this way, it will leave all parties dissatisfied and newcomers confused about the rationale for the law. This might well weaken the motivating force of the law (or principle), and might even lead to contempt for the law (or morality) as an institution. In extreme cases, this kind of law (or principle) might make no sense to anyone. Now although this might lead us to be suspicious of the desirability of pluralistic societies and of the method of compromise to resolve disputes, the problems raised seem to have little to do with vagueness as such and nothing to do with slippery-slope problems.

I shall conclude by returning to the quoted passage from Reichel and Dyck with which we began. First, the worry expressed in this passage about the preoccupation in contemporary industrialised societies with cost-containment is real enough but it would be worse than fanciful to suppose that we can entirely avoid cost-benefit considerations when allocating financial resources. Resources for medical treatment and research will always be scarce and the possibilities for further reallocation of funds from the healthy to the ill are endless and will always be with us. The decision about how much to allocate and where is unavoidable. Second, no force is presented, or even hinted at, that will drive us to move from a concern for what is beneficial to the patient voluntary euthanasia - to an overriding concern with what is beneficial to society - a desire to minimise expenditure on unprofitable services. Finally, let us note how preposterous it is to invoke Lifton in support of a Great Argument whose target is euthanasia. Lifton was fastidious in stressing the distinction between euthanasia, as understood in the AngloAmerican tradition, and 'euthanasia', as understood by the Nazis (9). The former is concerned solely with the alleviation of the suffering of the individual; the latter was concerned with curing a 'disease' afflicting the Volk and makes little or no sense outside the context of an organic theory of the social group. If Reichel and Dyck have identified a slide which we should genuinely fear, it is a slide into a society in which a concern for cost-containment comes entirely to obliterate concern for the individual. This would indeed be disastrous; but it would be so, whether or not euthanasia were legalised along the way.

\section{Acknowledgements}

I should like to acknowledge that my research was supported by an Australian National Health and Medical Research Council grant to Professor $\mathbf{P}$ Singer, Ms E Gaze and Dr H Kuhse. I should like to thank Helga Kuhse and Peter Singer for helpful comments on earlier drafts.

\section{References and notes}

(1) Reichel W, Dyck A J. Euthanasia: a contemporary moral quandary. The Lancet 1989 Dec 2: 13211323: page 1322

(2) See, for example Capron A M. The right to die: progress and peril. Euthanasia review 1987; 2: 41-59: page $53 \mathrm{ff}$.

(3) Lamb D. Down the slippery slope: arguing in applied ethics. London: Croom Helm, 1988.

(4) In view of the fact that dozens - possibly hundreds have recently produced versions of what I have been calling the Great Argument, an explanation is required of my reasons for choosing Reichel, Dyck and Lamb as targets. Reichel and Dyck are of interest for two reasons. First, they have produced an argument that is more detailed than most. Second, they were prepared to advance a crude slope argument, even though they were aware of literature that should have alerted them to its crudity. In the case of Lamb, the interest lies in the fact that he was sufficiently impressed with the Great Argument to structure an entire book around it.

(5) See reference (3): 19

(6) See reference (3): $36-37$

(7) See reference (3): 37.

(8) In compiling the list, I have drawn heavily for confirmation of my own intuitions and, in some places for inspiration, on Robert Jay Lifton, The Nazi doctors, 
New York: Basic Books, 1986, in particular, but also on Elias Canetti, Crowds and power, New York: Viking, 1962. When I first decided that an antidote to the Great Argument was long overdue, I thought that the decisive step would be to point out the existence of subtle, modest, detailed and cautious analyses of the aetiology of genocide and to contrast these with the sloppy and unscholarly fear-mongering of those who rely on the Great Argument. Dream on. The quote from Reichel and Dyck with which we began actually contains a footnote to Lifton. The point stressed by Lifton that even after one has made a detailed study of the Nazi period, there is something about social groups and the darker side of the human psyche which makes that period, and other such episodes, deeply mysterious - perhaps ultimately inexplicable - seems completely to have passed those authors by.

(9) See reference (8): 46.

\section{News and notes}

\section{Quality '93: Raising Quality in the NHS: What Progress?}

Quality '93, to be held on 11 November at The Brewery, London EC1, follows the success of Raising Quality in the NHS in March 1992.

Quality '93 is being organised by the BMA, the BMJ, the Kings Fund, the College of Health and Quality in Health Care. The meeting will review progress with raising quality in the NHS and also look at what's new in raising quality. A particular focus will be on involving patients in raising quality.

The meeting is open to doctors, nurses, all health professionals, managers, politicians, researchers, policy makers and members of the public.

For further details contact: Pru Walters, BMA House, Tavistock Square, London WC1H 9JP, Telephone: 0713836518. 